\title{
Exploring Nurse and Patient Experiences of Developing Rapport During Oncology Ambulatory Care Videoconferencing Visits: Protocol for a Qualitative Study
}

Paula D Koppel", MS, RN, GNP-BC, AHN-BC, NBC-HWC; Jennie C De Gagne*, PhD, DNP, RN, NPD-BC, CNE

Duke University School of Nursing, Durham, NC, United States

*all authors contributed equally

Corresponding Author:

Paula D Koppel, MS, RN, GNP-BC, AHN-BC, NBC-HWC

Duke University School of Nursing

DUMC 3322

307 Trent Drive

Durham, NC, 27710

United States

Phone: 16178357087

Email: paula.koppel@duke.edu

\begin{abstract}
Background: Telehealth videoconferencing has largely been embraced by health care providers and patients during the COVID-19 pandemic; however, little is known about specific techniques for building rapport and provider-patient relationships in this care environment. Although research suggests that videoconferencing is feasible and can be effective for some types of care, concerns about the impact of technology on provider-patient relationships exist across health disciplines. Suggestions for adapting some in-person rapport techniques, such as the use of small talk, eye contact, and body language to facilitate trust, personal connection, and communication during videoconferencing encounters, have been discussed in the popular press and clinical commentaries. Notably, evidence regarding the effects of these strategies on rapport and clinical care outcomes is lacking. Understanding how to establish rapport in videoconferencing visits is especially important in oncology nursing, where rapport with patients enables nurses to become a source of emotional support, helping patients adapt and navigate the cancer journey.
\end{abstract}

Objective: This study aims to investigate the nature of nurse-patient rapport in ambulatory cancer care videoconferencing visits. The objectives include exploring how patients with cancer and nurses describe experiences of rapport and strategies for cultivating rapport in videoconferencing visits and similarities and differences identified by patients with cancer and nurses between experiences of rapport in videoconferencing and in-person visits.

Methods: Semistructured narrative interviews of patients with cancer and nurses will be conducted to understand the experience of rapport building in videoconferencing visits. Nurses and patients will be interviewed separately to facilitate an understanding of the perspectives of both types of participants. Interviews will be conducted on a secure videoconferencing platform. This qualitative descriptive study will describe participant experiences in a manner that, although not without interpretation, is as close to the data as possible. The research team will meet regularly to discuss, define, and document codes, categories, and themes, and the team will maintain a detailed audit trail of analytical decisions. In addition, member checking will enhance the rigor of the study. Nurse and patient interviews will be analyzed separately using identical procedures and may be explored side by side in the final analysis to provide a comparative analysis. Data management and analysis will be performed using NVivo 12.

Results: Data collection will begin during summer 2021, with results from the data analysis anticipated by winter 2021. A research team trained in qualitative methodology will use conventional content analysis to analyze the data using first- and second-level codes derived directly from the transcribed text data.

Conclusions: This study aims to determine what behaviors, communication techniques, and relational practices need to be adapted in videoconferencing telehealth visits, setting the foundation for future development of interventions and evidence-based practice guidelines for relationship building during videoconferencing telehealth visits.

International Registered Report Identifier (IRRID): PRR1-10.2196/27940

(JMIR Res Protoc 2021;10(6):e27940) doi: 10.2196/27940 


\section{KEYWORDS}

nursing; oncology ambulatory care; provider-patient relationship; rapport; telehealth; videoconferencing visits

\section{Introduction}

\section{Background}

When the replacement of ambulatory in-person visits with videoconferencing suddenly became essential for persons with cancer because of the COVID-19 pandemic, providers had little experience or existing research to support this change in practice $[1,2]$. Some oncology ambulatory care centers went from all in-person visits to more than $50 \%$ of patient visits on videoconferencing [3]. Although videoconferencing has been broadly embraced by providers and patients during the pandemic, little is known about specific techniques for building rapport and provider-patient relationships in this care environment.

Review studies of videoconferencing in telehealth, although often focused on feasibility and acceptability for patients who are geographically underserved, show that this computer-mediated modality has utility and even comparable outcomes with in-person care for patients with a variety of chronic diseases and mental health challenges [4-7]. A systematic review of 15 studies conducted in oncology suggests that videoconferencing is feasible and can be effective in the care of some cancers [8]. More recent studies have focused on videoconferencing for palliative care consultation and support to patients, family caregivers, and community-based care providers [9-11]. These studies indicate that videoconferencing is feasible and often preferable for palliative care consultations $[11,12]$, hospice family meetings $[13,14]$, and support groups [15].

\section{Knowledge Gaps}

Although research suggests that videoconferencing is feasible and can be effective for some types of care, concerns about the impact of technology on provider-patient relationships exist across health disciplines. Nurses, physicians, and mental health providers have expressed concern that the two-dimensional interactions in video conferencing coupled with the loss of physical proximity, presence, and touch depersonalizes care and inhibits the providers' ability to best understand the patient and demonstrate care [16-19]. In palliative care studies, providers have indicated a reluctance to initiate emotional topics, feeling a need to be physically present with the patient to provide necessary support [20,21]. Reluctance has also been described because providers cannot be sure that patients have adequate privacy in videoconferencing visits [14]. Suggestions for adapting some in-person rapport techniques such as the use of small talk, eye contact, and body language to facilitate trust, personal connection, and communication during videoconferencing encounters have been discussed in the popular press and clinical commentaries [1,22-24]. However, few studies seem to have evaluated these modalities [25-28] or more advanced relational skills such as presence [29], conveying caring [30], empathy [31], and person-centered care [32]. Even in telepsychology, where research is more robust [33], providers remain concerned about the impact of videoconferencing on therapeutic alliance and nonverbal communication channels $[16,34]$ and are uncertain about how best to adapt techniques.

\section{Importance of Nurse-Patient Rapport}

Rapport has been defined as a connection established with another person based on respect, acceptance, empathy, and a mutual commitment to engagement $[35,36]$. Interpersonal interventions that cultivate rapport between patients and providers have the potential to improve patient health outcomes and satisfaction [37,38]. For persons with cancer, feeling known personally and connected with nurses and health care providers on a level beyond their disease process reduces suffering and improves satisfaction, health outcomes, and quality of life [39-41]. Being known beyond their disease includes acknowledging the roles that patients have outside of being a person with cancer, including their personal and professional roles, and interacting with them as people rather than as patients $[39,42]$. Research suggests that rapport makes a trusting and therapeutic relationship more likely $[43,44]$ and, in turn, enables providers to become a source of emotional support, helping patients adapt and navigate the cancer journey [35,45-47]. The cancer journey is often a prolonged experience that spans diagnosis, treatment, and years of survivorship with ongoing care and multiple comorbidities [48]. Having a nurse who is not only knowledgeable but who can also provide a whole-person approach to care is essential. Ambulatory oncology nurses play a pivotal role in a patient's cancer journey by helping patients and families integrate new information and build the capacity and skills to adapt and address care challenges $[47,49]$. For example, a patient with cancer who lives alone or has a baseline mobility impairment may require a very different plan of care to successfully manage common side effects such as nausea, vomiting, and diarrhea. As such, nurse-patient rapport facilitates the trusting relationship necessary to ensure holistic assessment of needs, personalization of care, and adaptive work [39,50-52].

\section{Critical Need for Research}

Studies suggest that relationship development and communication in videoconferencing encounters, although similar to in-person interactions, present unique challenges that can affect rapport, diagnostic accuracy, and treatment compliance when not addressed [25,28]. For example, camera placement and the ability to visualize the self during videoconferencing platforms create both a downward gaze [53] and excessive levels of gaze [54] that are unnatural when compared with in-person encounters. In addition, video and audio lapses that result in overlapping conversations or uncomfortable periods of silence interfere with communication [28]. Studies comparing in-person and videoconferencing encounters have found that providers use less empathetic, supportive, and facilitating statements [31] in virtual encounters, and there is less information exchange, with the presentation of fewer problems [55]. Of note, evidence regarding the effects of these findings on rapport and clinical care outcomes is lacking. 


\section{Research Aim and Questions}

The purpose of this qualitative descriptive study is to explore the nature of nurse-patient rapport in ambulatory cancer care videoconferencing visits. The use of videoconferencing in telehealth nursing is relatively new, especially in oncology ambulatory care. With little existing research to build on, prioritizing studies that provide a foundation for future inquiries is essential. This gap requires a descriptive, exploratory study to increase our understanding of nurse-patient rapport in such a context. Knowledge gaps include an understanding of the attributes of videoconferencing experiences for nurses and patients, along with antecedents, facilitators, barriers, and outcomes. The proposed study will address (1) how patients with cancer and nurses describe experiences of rapport and strategies for cultivating rapport in videoconferencing visits and (2) similarities and differences identified by patients with cancer and nurses between experiences of rapport in videoconferencing and in-person visits.

\section{Methods}

\section{Overview of the Study Design}

Nurses and patients will be interviewed separately to ensure that both can speak freely about their experiences and to facilitate understanding of the perspectives of both types of participants. Semistructured interviews will be conducted on Zoom (Zoom Video Communications), a secure videoconferencing platform. Narrative interviewing guidelines will be used, providing participants with the opportunity to describe their experiences before the researcher asks any probing questions. This approach aligns with our qualitative descriptive methodology by focusing on how participants describe their experience of rapport using everyday language to provide insight on videoconferencing [56]. As suggested by Sandelowski [56,57], a descriptive qualitative approach focuses on participants' descriptions of their experiences while limiting the interpretation of meaning to only what is directly reported by the participant. Unlike a phenomenological approach, which deeply explores a few homogenous participants' lived experiences, this study will include enough participants to comprehensively describe the experiences of nurse-patient rapport in the new context of videoconferencing in ambulatory oncology [56,57]. Qualitative descriptive research provides rich, in-depth descriptions of experiences that are not feasible with quantitative approaches [58]. This study aims to uncover patterns and themes concerning how rapport is experienced during videoconferencing visits to provide a foundation for the development of practice guidelines.

\section{Participants and Setting}

The study recruitment, consent process, and data collection will be conducted remotely because of COVID-19 restrictions. Stratified purposive sampling will be used to recruit participants from an academic ambulatory oncology center in the northeastern United States. Providers at this center have had recent experiences with videoconferencing visits to provide rich data about these encounters. Stratification will include the number of telehealth videoconferencing visits that patients and nurses have experienced. The literature suggests that the level of experience influences ease of use and perceptions of telehealth videoconferencing visits [4]. Patients will be stratified into 2 groups (ie, $\leq 2$ and $>2$ videoconferencing visits). Nurses will be stratified into 2 groups (ie, 10-20 and $>20$ videoconferencing visits). Further stratification may be added to ensure that the sample is diverse, with various perspectives from participants of different ages, backgrounds, and experiences. Participants will be asked to share self-identified information, including age, gender identity, race, ethnicity, household income (patients), education, length of time receiving care (patients) or duration of employment (nurses) at the ambulatory care clinic, and the estimated number of telehealth videoconferencing calls that they have participated in as patient or nurse during the last 12 months. The exact size of the final sample will depend on data saturation in each of the 4 stratified groups and be large enough to capture the rich experiences of nurses and patients but small enough to permit a thorough analysis of the data [59]. Recruitment will end when no new themes related to the research questions are identified, indicating data saturation [60]. Participants who do not have access to technology and adequate broadband width to support videoconferencing will be excluded from the study. As this proposed study aims to analyze the experiences of individuals who have this technology and experience, future studies that will focus on patients with limited technology access are planned.

\section{Inclusion and Exclusion Criteria}

The inclusion criteria for patients are (1) adults (aged $\geq 18$ years), (2) able to read and converse in English, (3) receiving care and undergoing active treatment at the identified oncology ambulatory care center, (4) have participated in at least one videoconferencing visit with a nurse from the identified oncology ambulatory care center within 3 months before the interview, and (5) enrollment in the oncology ambulatory care center's secure web-based platform with the necessary technology to conduct the videoconferencing interview. Patients with a medical diagnosis related to cognitive impairment (eg, Alzheimer disease or related dementias) will be excluded. The inclusion criteria for nurses are (1) licensed registered or advanced practice nurses employed at the oncology ambulatory care center for at least a year after orientation and (2) participation in videoconferencing visits with patients at the identified oncology ambulatory care center.

\section{Ethical Considerations}

The institutional review board (IRB) application for this study is currently under review. The Center for Research in Nursing and Patient Care Services within the cancer center supports the facilitation of this study. The applicant's university IRB will also review the proposal after it has been approved by the cancer center. Approval from both participating IRBs will be received before beginning the study. Written informed consent will be obtained from all participants before data collection.

The research methods, including qualitative interviews and asking for demographic information, involve minimal risk to participants. A study information sheet, which includes the study purpose and activities as well as the primary researcher's contact information, will be provided electronically to 
participants. This will allow participants to contact the research team directly. This information will also be shared verbally during the consent process and included in the informed consent form. Participants will be informed that their participation is voluntary and can be stopped or rescheduled at any time. Participants will also be informed that they can withdraw from the study at any time without any impact on their care or employment. The researchers will maintain open and honest communication throughout the process and create an environment of trust and safety by answering all questions and allowing participants as much time as necessary. Patients will be allowed to include their informal caregivers in this process because the literature suggests that such inclusion may reduce the burden of the recruitment process for patients with cancer [61]. However, informal caregivers will not be interviewed and will be asked to allow the patient to answer all the interview questions independently.

Care will be taken to contextualize any data that could potentially threaten the confidentiality and privacy of participants. For example, exemplar quotations will simply refer to participants by number or pseudonym when presenting the results. Data collected from participants will be deidentified and used only for research purposes and associated dissemination. Participants will be assigned unique identification numbers that will be used on all data collection forms and data files (ie, interviews, transcripts, and demographic questionnaires). Electronic files, including the key for the unique identification numbers and corresponding participant names, will be stored on the researchers' computers on a secure password-protected hard drive or server with firewall protection and multifactor authentication. Any hard copies of transcripts or field notes will be stored in a double-locked location. Only members of the research team will have access to the electronic and printed files. Interviews will be conducted on Zoom, the institution-approved secure videoconferencing platform with approved data management and security features that allow secure recording and storage without recourse to third-party software. Zoom security measures include user-specific authentication, real-time encryption, and the ability to back up recordings to the aforementioned secure password-protected server.

Participation in this study offers no direct benefits to the nurses or patients who participate. However, participants may find it beneficial to discuss and reflect on their encounters and the nurse-patient relationship. They may also feel a sense of satisfaction from contributing to the advancement of knowledge and future practice implications attributed to the study. Nurses and patients will be invited to attend the presentation of the study results. Evidence demonstrates that both patients with cancer [61] and nurses [62] often gain a sense of fulfillment when participating in research.

\section{Recruitment}

Conducting interviews on the institution-approved platform will allow recruitment and data collection to proceed even as social distancing is maintained during the ongoing pandemic. Recruitment of participants will be carried out at the oncology clinics at the ambulatory care center where nursing videoconferencing is currently part of the care process. Nurses and patients will be recruited through a combination of efforts, including announcements at nursing staff meetings, postings on a web-based study recruitment message board, and the distribution of study brochures. Nurses will be recruited into the study first, and they will be invited to share the study information sheet with eligible patients. Interest in, and support for the study has been obtained from the cancer center's nursing leadership, who will foster opportunities for the research study to be presented to nursing staff. Nurses will self-identify and be asked to share the study brochures with patients who may be potential participants in the study. Information about the study in web-based research bulletins will also allow patients to self-identify. Participants interested in participating in the study will be screened and provided information on the study and informed consent by the researchers through telephone or email. A time for the interview will also be agreed upon. The written consent and demographic data collection will be carried out through Research Electronic Data Capture at the time of the interview. All patient and nurse interviews will be conducted on the institution-approved videoconferencing platform to ensure a secure encounter. Patients will be allowed to include their informal caregivers in this process because the literature suggests that this reduces the burden of the recruitment process for patients with cancer [61]. Although the concern for adding burden to patients with cancer is legitimate, evidence suggests that patients with cancer often find meaning in the disease process by participating in research [61,62]. No subjects will be excluded from the study based on age, self-reported gender identity, race, or ethnicity, except where necessary to meet the inclusion and exclusion criteria.

\section{Data Collection Procedures}

Individual nurses and patients will be interviewed separately. Interviews will be conducted on Zoom, the institution-approved platform, which is used by the ambulatory care center. Using the institution-approved platform will ensure that the participants are familiar with the technology and will also prompt memories of their experiences of rapport in videoconferencing encounters. Videoconferencing has been shown to be a feasible and acceptable vehicle for collecting qualitative data, with both researchers and participants reporting high levels of satisfaction [63], and a comparison of in-person interviews with videoconferencing interviews found little difference in the development of interviewer rapport [64]. Interviews will be audio recorded and transcribed to allow analysis of these text-based data. Data analysis will be ongoing and occur concurrently with data collection.

Interview guides for nurse and patient participants are under development by the research team to direct the semistructured interviews. Seminal research by Radwin [46] and Thorne [41] on the perceptions of patients with cancer of clinical care are guiding the development of the interview guide. The interviews will use a narrative format with 4 phases: initialization, main narrative, questioning, and closure [65]. During the initialization phase, participants will be asked to confirm their understanding that the interview is being recorded. The purpose of the interview will be described as, "This is an opportunity to share your experiences of having videoconferencing visits with your 
oncology nurse." A grand tour question will be used to initiate the interview: "Please describe your thoughts and feelings about having visits with your oncology nurse via videoconferencing." Per narrative interviewing guidelines, participants will be given an opportunity to tell their complete story (main narrative phase) about their experiences before the interviewer asks any probing follow-up questions [65]. In the questioning phase of the interviews, participants will be asked to describe their experiences of rapport in nurse-patient interactions during both in-person and videoconferencing encounters. Follow-up questions will be used to probe more deeply after the initial responses to provide rich, detailed descriptions. For example, participants will be asked to reflect on how experiencing rapport in videoconferencing visits was similar to, or different from, their in-person experiences. In addition, a broad question will be used to explore whether the participants felt that strategies or contextual issues (ie, technology challenges, two-dimensional nature of the relationship, ability to detect facial features or body language, lack of touch or other sensory stimulation) may have affected their experience of rapport in videoconferencing visits either positively or negatively. Questions for nurses and patients, although similar, will be slightly modified, given their differing roles. Before concluding, the interviewer will ask participants if there is anything else that they want to share. The guide for patients can be found in Textbox 1 .

Textbox 1. Patient interview guide.

Grand Question (Start Here): Please Describe Your Thoughts and Feelings About Having Videoconferencing Visits With Your Nurses

- $\quad$ Follow-up probing questions

- How would you describe rapport?

- How do you experience rapport with your nurse in a videoconferencing visit? For example, what does it look like and how does it feel? How does it feel and look when you do not have rapport with your nurse?

- How do you go about developing rapport with your nurse in a videoconferencing visit?

- How does the experience of rapport with your nurse in a videoconference visit compare with a traditional in-person encounter? What are the differences in your visits when videoconferencing is used? Is it easier to establish rapport in-person?

- How does having a videoconference visit affect your ability to communicate with your nurse?

- What factors do you think may be influencing or have an impact on your ability to build rapport with your nurse in videoconferencing visits?

- Would you want to continue videoconferencing visits once the COVID-19 pandemic is controlled? Why or why not?

- Is having rapport important to you and if so, why or why not?

- Is there anything else you would like to share with me?

\section{Data Management and Analysis}

\section{Overview}

Conventional content analysis will be used to analyze the qualitative data collected in this study. This approach is useful in exploring areas where little is known and robust descriptive data are needed to better understand the research questions $[66,67]$. The purpose of this study is to understand how rapport is described and evolves within the context of this new clinical setting by focusing on manifest content rather than symbolic meaning (latent content). By focusing on manifest content, the analysis is firmly placed in the realm of content analysis rather than thematic analysis or other approaches, such as narrative, discourse, or semiotic analysis $[67,68]$. Codes will be derived directly from the transcribed text data, keeping the coding close to the participants' descriptions [56,67]. Nurse and patient interviews will be analyzed separately using identical procedures. The content analysis management process described by Elo and Kyngäs [66] will be used to organize the analysis process. This management process includes 3 phases: preparation, organization, and reporting.

\section{Preparation Phase}

With each interview representing the unit of analysis for this study, data preparation will include reading through each entire transcript while listening to the entire interview and noting important topics in the margin. The data preparation phase allows for immersion in the text data and for the researchers to become familiar with each case as a whole [66]. After reading each transcript, a summary analytic memo will be initiated to capture overall impressions, a holistic view of the interview, contextual information that might have influenced the interview, and any personal perceptions [69]. The data preparation phase will also make transparent any research team member beliefs or experiences elicited by the data that require bracketing [69].

\section{Organizational Phase}

The goal of the organizational phase is to label and condense the data into meaningful units, allowing patterns and relationships within the units to emerge. Initially, research team members will go line by line through the transcript, applying meaningful codes [67]. An inductive approach that allows the codes to emerge from the data will be used. Coding is often divided into 2 levels [69]. First-level coding methods assign codes to data units as they are read line by line again. There are many first-level coding methods, but based on this study's aim to capture the interpersonal experiences of nurses and patients who participate in videoconferencing visits, the coding method will likely involve both process and emotional coding [69]. Process coding captures interactions and outcomes, whereas emotional coding is useful for descriptions of intrapersonal and 
interpersonal experiences [69]. In addition, codes using the participants' own words, also called in vivo coding, may provide rich labels that are authentic to participants' experiences [69]. To support the exploration of the data, team members will consider codes that answer questions (ie, what, who, how, when, where, why), capture actions (eg, watching, listening, advocating), and describe characteristics of the experience (eg, supportive, encouraging, warm, interested). This first-level coding approach is purposefully selected to represent the manifest content of the data rather than its symbolic meaning [69].

Second-level coding will explore relationships and patterns in the data, resulting in categories and themes [66]. This process will be intentionally iterative to keep the analysis as close as possible to the participants' accounts, encompassing the experiences of all the participants interviewed, with ideas emerging to either confirm data already analyzed or provide new data that need verification [56,70]. Analyses will include creating, defining, and recording codes, categories, and themes and matching the themes with exemplar quotations. After separate analyses of patient and nurse data have been completed, a comparison of the data will allow the exploration of similarities and differences. This analysis may result in additional themes for the final reporting phase [66].

Code names, definitions of codes, and exemplar quotes will be constructed in a codebook using the data analysis management tool NVivo 12.0 (QSR International Pty Ltd). During the initial weeks of the analysis, the authors will individually code the same cases and meet as a team to compare and define codes. Once all research team members agree on the coding of $20 \%$ of the transcripts, a codebook will be created to guide coding of the remaining transcripts. The team will continue to meet to discuss new codes and revise the codebook as needed. As the codebook evolves and agreement between team members becomes consistent, team members will code different cases. Bimonthly scheduled coding meetings will be used to discuss and clarify the coding of uncertain data segments. Suggested codebook revisions will always be discussed until an agreement is reached. Changes will be documented in analytical memos to ensure documentation of the process and clear, consistent data coding. Any revisions in codes will require revisiting the previous coding to ensure the integrity of the analysis.

\section{Reporting Phase}

The final phase of the analysis process is reporting. Exemplar quotes from the participants will be used as evidence of the findings [66,67]. As nurse and patient interviews will be analyzed separately, data reporting will reflect themes for each group separately but may be presented side by side to illustrate a comparative analysis. The findings will be evaluated within the context of related theories and evidence-based research $[66,67]$. A narrative of the final analysis will create a story of the data, adding insight and new knowledge [66,71].

\section{Plan for Ensuring Rigor or Trustworthiness of Findings}

The study's rigor, also described as trustworthiness in qualitative research $[60,70]$, will be enhanced by (1) conducting all analyses as a research team (ie, a nursing doctoral student well versed in qualitative research and a nurse faculty researcher with 15 years of qualitative research experience), with weekly coding meetings to discuss and define all codes, categories, and themes; (2) collecting and analyzing the data concurrently, listening carefully while remaining open to the emergence of unexpected findings, and being willing to let go of poorly supported ideas [70]; (3) using detailed memos to create an audit trail of analytical decisions $[60,72]$; (4) confirming that the categories represent expansive and diverse experiences with exemplar quotations from multiple participants [60,73]; and (5) using member checking techniques by asking participants clarifying questions during the interviews [60]. The Consolidated Criteria for Reporting Qualitative Research checklist will be used to guide the reporting of the study results [74].

Risks for bias in general include the effects of the researcher on the participants; the effects of the participants on the researcher; and the researcher's own perspectives, experiences, assumptions, values, and beliefs. More specific risks for bias include the influence of COVID-19 as the context that increased the use of videoconferencing, level of experience of the participants with videoconferencing, and the use of nurses to help with recruitment. In qualitative research, the researcher is the instrument [60], and this is reflected in the strategies used to enhance the rigor and trustworthiness described previously. In large measure, rigor will be enhanced with reflexivity strategies that include ongoing memos with researcher self-reflections. This transparency will also enhance the research team's capacity to remain receptive to new emerging findings during the analysis process [60]. The interview guide, developed by the researchers, is based on a systematic review of the literature, and the narrative interview approach involves starting with a grand question that is designed to allow the participant's experience to guide the interview. In addition, stratified purposive samples will be used to ensure collection of data from participants who have multiple perspectives, and the nurses who assist in recruitment will be asked to offer the study information to all their patients who meet the study criteria. This will reduce the risk of nurses only telling a particular group of patients about the study (ie, patients with whom they share a good rapport). Finally, a presentation of the findings will be set within the context of the pandemic.

\section{Results}

\section{Study Status}

IRB approval will be obtained before beginning data collection. Data collection will begin during summer 2021, with analysis expected to be completed by winter 2021 .

\section{Anticipated Results}

Few studies have focused exclusively on rapport building in videoconferencing [21]; however, rapport is often mentioned in research conducted on telehealth videoconferencing visits. These incidental findings provide some clues to our expected results. For example, studies often highlight how the visual component of videoconferencing makes relationship building easier compared with telephonic consultation [21,75-77]. Other studies suggest that adjustments to the background, camera 
positioning, and volume, along with the increased use of verbal confirmations during the interaction, are useful $[21,29,75,78]$. Helping patients navigate technology with a positive attitude, including the use of in-person support to provide the caring touch and hands-on technical assistance, has been reported to enhance rapport $[29,54,79,80]$.

Unique barriers to rapport in videoconferencing visits have also been reported as secondary findings, and they include uncertainty around patient privacy $[9,12,21,79]$, loss of sensory input owing to the limited view of the peripheral space and full visualization of body language [14,54,81], loss of physical connectedness $[21,29,79]$, and patients being left out in provider exchanges [82,83]. Finally, technology failures have been described as having a negative impact on rapport [29,81].

By focusing our exploration exclusively on patient-nurse rapport in oncology ambulatory videoconferencing visits, this study seeks to fully describe this experience from both nurse and patient perspectives. The study will also seek to understand the unique challenges, facilitators, and barriers to developing and experiencing rapport in these computer-mediated encounters. This investigation may validate some of the incidental findings from other studies or uncover new considerations.

\section{Discussion}

\section{Study Significance}

A strong and supportive nurse-patient relationship is especially important for persons with cancer. Looking at how the movement toward videoconferencing visits during the COVID-19 pandemic affects the nurse-patient relationship and the capacity to maintain high quality, supportive cancer care is essential, given the likelihood that telehealth videoconferencing visits will become an enduring component of cancer care. Although caring within the videoconferencing technological environment may require adapting our practices, it must not detract from the essential nature of nursing. One view of caring in a technological medium is described by Locsin and Purnell [19] in their theory, Technological Competency as Caring in Nursing. This midrange theory views technology as a complementary opportunity that can facilitate knowing and connection [19]. The nurse's technological competency is seen as another way of caring $[19,84]$. From this vantage point, videoconferencing visits can be a way to maintain human connectedness during the pandemic or even beyond. Technological Competency as Caring in Nursing describes the human connection and communication between the nurse and patient as a cocreated moment essential to protecting humanness and preventing patients from becoming objects of care in technological environments [19].

\section{Conclusions}

The pandemic makes this exploration of rapport in telehealth videoconferencing with nurses and patients timely. The rapid and successful use of videoconferencing visits, coupled with potential benefits to patients, providers, and health care systems, suggests that patient care using this technology will likely continue to be a significant component of oncology ambulatory care even after the pandemic has subsided [2,85-87]. This research will help determine what behaviors, communication techniques, and relational practices need to be adapted to advance effective nurse-patient rapport in oncology videoconferencing visits. This study will set the foundation for developing interventions and evidence-based practice guidelines for developing a nurse-patient therapeutic relationship during videoconferencing telehealth visits.

\section{Authors' Contributions}

PDK and JCDG designed the study protocol. PDK drafted the initial manuscript, and JCDG contributed to critical reviews and revisions of the manuscript. All authors approved the final manuscript and agreed to its publication.

\section{Conflicts of Interest}

None declared.

\section{References}

1. Car J, Koh GC, Foong PS, Wang CJ. Video consultations in primary and specialist care during the Covid-19 pandemic and beyond. Br Med J 2020 Oct 20;371:m3945. [doi: 10.1136/bmj.m3945] [Medline: 33082127]

2. Leung MS, Lin SG, Chow J, Harky A. COVID-19 and oncology: service transformation during pandemic. Cancer Med 2020 Oct 18;9(19):7161-7171 [FREE Full text] [doi: 10.1002/cam4.3384] [Medline: 32810386]

3. Darcourt JG, Aparicio K, Dorsey PM, Ensor JE, Zsigmond EM, Wong ST, et al. Analysis of the implementation of telehealth visits for care of patients with cancer in Houston during the COVID-19 pandemic. JCO Oncol Pract 2021 Jan;17(1):36-43. [doi: 10.1200/OP.20.00572] [Medline: 33026951]

4. Almathami HK, Win KT, Vlahu-Gjorgievska E. Barriers and facilitators that influence telemedicine-based, real-time, online consultation at patients' homes: systematic literature review. J Med Internet Res 2020 Feb 20;22(2):e16407 [FREE Full text] [doi: 10.2196/16407] [Medline: 32130131]

5. Ignatowicz A, Atherton H, Bernstein CJ, Bryce C, Court R, Sturt J, et al. Internet videoconferencing for patient-clinician consultations in long-term conditions: a review of reviews and applications in line with guidelines and recommendations. Digit Health 2019;5:A [FREE Full text] [doi: 10.1177/2055207619845831] [Medline: 31069105]

6. Penny RA, Bradford NK, Langbecker D. Registered nurse and midwife experiences of using videoconferencing in practice: a systematic review of qualitative studies. J Clin Nurs 2018 Mar 11;27(5-6):739-752. [doi: 10.1111/jocn.14175] [Medline: 29149507] 
7. Speyer R, Denman D, Wilkes-Gillan S, Chen Y, Bogaardt H, Kim J, et al. Effects of telehealth by allied health professionals and nurses in rural and remote areas: a systematic review and meta-analysis. J Rehabil Med 2018 Mar 28;50(3):225-235 [FREE Full text] [doi: 10.2340/16501977-2297] [Medline: 29257195]

8. Kitamura C, Zurawel-Balaura L, Wong RK. How effective is video consultation in clinical oncology? A systematic review. Curr Oncol 2010 Jun 26;17(3):17-27 [FREE Full text] [doi: 10.3747/co.v17i3.513] [Medline: 20567623]

9. Funderskov KF, Danbjørg DB, Jess M, Munk L, Zwisler AO, Dieperink KB. Telemedicine in specialised palliative care: healthcare professionals' and their perspectives on video consultations-a qualitative study. J Clin Nurs 2019 Nov 09;28(21-22):3966-3976. [doi: 10.1111/jocn.15004] [Medline: $\underline{\text { 31328336] }}$

10. Jess M, Timm H, Dieperink KB. Video consultations in palliative care: a systematic integrative review. Palliat Med 2019 Sep 12;33(8):942-958. [doi: 10.1177/0269216319854938] [Medline: 31187688]

11. Steindal SA, Nes AA, Godskesen TE, Dihle A, Lind S, Winger A, et al. Patients' experiences of telehealth in palliative home care: scoping review. J Med Internet Res 2020 May 05;22(5):e16218 [FREE Full text] [doi: 10.2196/16218] [Medline: 32369037]

12. Funderskov KF, Raunkiær M, Danbjørg DB, Zwisler A, Munk L, Jess M, et al. Experiences with video consultations in specialized palliative home-care: qualitative study of patient and relative perspectives. J Med Internet Res 2019 Mar 21;21(3):e10208 [FREE Full text] [doi: 10.2196/10208] [Medline: 30896436]

13. Bradford N, Young J, Armfield NR, Bensink ME, Pedersen L, Herbert A, et al. A pilot study of the effectiveness of home teleconsultations in paediatric palliative care. J Telemed Telecare 2012 Dec;18(8):438-442. [doi: 10.1258/jtt.2012.gth103] [Medline: 23155114]

14. Oliver D, Washington K, Wittenberg-Lyles E, Demiris G, Porock D. 'They're part of the team': participant evaluation of the ACTIVE intervention. Palliat Med 2009 Sep 14;23(6):549-555 [FREE Full text] [doi: 10.1177/0269216309105725] [Medline: 19443524]

15. Melton L, Brewer B, Kolva E, Joshi T, Bunch M. Increasing access to care for young adults with cancer: results of a quality-improvement project using a novel telemedicine approach to supportive group psychotherapy. Palliat Support Care 2017 Apr;15(2):176-180. [doi: 10.1017/S1478951516000572] [Medline: 27457109]

16. Brahnam S. Comparison of in-person and screen-based analysis using communication models: a first step toward the psychoanalysis of telecommunications and its noise. Psychoanal Perspect 2017 Apr 25;14(2):138-158. [doi:

10.1080/1551806x.2017.1304112]

17. Chhabra AM, Chowdhary M, Choi JI, Hasan S, Press RH, Simone CB. A national survey of radiation oncology experiences completing tele-consultations during the coronavirus disease (COVID-19) pandemic. Adv Radiat Oncol 2021 Jan;6(1):100611 [FREE Full text] [doi: 10.1016/j.adro.2020.10.024] [Medline: 33458451]

18. Grumme V, Barry C, Gordon S, Ray M. On virtual presence. Adv Nurs Sci 2016;39(1):48-59. [doi: 10.1097/ans.0000000000000103]

19. Locsin RC, Purnell M. Advancing the theory of technological competency as caring in nursing: the universal technological domain. Int J Hum Caring 2015 Jan;19(2):50-54. [doi: 10.20467/1091-5710-19.2.50]

20. Lally K, Kematick BS, Gorman D, Tulsky J. Rapid conversion of a palliative care outpatient clinic to telehealth. JCO Oncol Pract 2021 Jan;17(1):62-67. [doi: 10.1200/op.20.00557]

21. van Gurp J, van Selm M, Vissers K, van Leeuwen E, Hasselaar J. How outpatient palliative care teleconsultation facilitates empathic patient-professional relationships: a qualitative study. PLoS One 2015;10(4):e0124387 [FREE Full text] [doi: 10.1371/journal.pone.0124387] [Medline: 25902263]

22. Banerjee SC, Staley JM, Howell F, Malling C, Moreno A, Kotsen C, et al. Communicating effectively via tele-oncology (Comskil TeleOnc): a guide for best practices for communication skills in virtual cancer care. J Cancer Educ $2021 \mathrm{Mar}$ 05:1-6 [FREE Full text] [doi: 10.1007/s13187-021-01959-7] [Medline: 33544315]

23. Chua IS, Jackson V, Kamdar M. Webside manner during the COVID-19 pandemic: maintaining human connection during virtual visits. J Palliat Med 2020 Nov;23(11):1507-1509. [doi: 10.1089/jpm.2020.0298] [Medline: 32525744]

24. IHI Multimedia Team. Tips you may not know to improve telehealth for patients and providers. Institute for Healthcare Improvement. $2020 \mathrm{Jul} 21$. URL: http://www.ihi.org/communities/blogs/ tips-you-may-not-know-to-improve-telehealth-for-patients-and-providers [accessed 2021-05-30]

25. Dalley D, Rahman R, Ivaldi A. Health care professionals' and patients' management of the interactional practices in telemedicine videoconferencing: a conversation analytic and discursive systematic review. Qual Health Res 2021 Mar 01;31(4):804-814. [doi: 10.1177/1049732320942346] [Medline: $\underline{32741261]}$

26. Henry B, Ames L, Block D, Vozenilek J. Experienced practitioners' views on interpersonal skills in telehealth delivery. Internet J Allied Health Sci Pract 2018;16(2):Art 2 [FREE Full text]

27. Newcomb AB, Duval M, Bachman SL, Mohess D, Dort J, Kapadia MR. Building rapport and earning the surgical patient's trust in the era of social distancing: teaching patient-centered communication during video conference encounters to medical students. J Surg Educ 2021 Jan;78(1):336-341 [FREE Full text] [doi: 10.1016/j.jsurg.2020.06.018] [Medline: 32709566]

28. Shaw SE, Seuren LM, Wherton J, Cameron D, A'Court C, Vijayaraghavan S, et al. Video consultations between patients and clinicians in diabetes, cancer, and heart failure services: linguistic ethnographic study of video-mediated interaction. J Med Internet Res 2020 May 11;22(5):e18378 [FREE Full text] [doi: 10.2196/18378] [Medline: 32391799] 
29. Barrett D. Rethinking presence: a grounded theory of nurses and teleconsultation. J Clin Nurs 2017 Oct 24;26(19-20):3088-3098. [doi: 10.1111/jocn.13656] [Medline: 27874982]

30. Sitzman K. Evolution of Watson's human caring science in the digital age. Int J Hum Caring 2017 Feb 01;21(1):46-52. [doi: $10.20467 / 1091-5710.21 .1 .46]$

31. Liu X, Sawada Y, Takizawa T, Sato H, Sato M, Sakamoto H, et al. Doctor-patient communication: a comparison between telemedicine consultation and face-to-face consultation. Intern Med 2007;46(5):227-232 [FREE Full text] [doi: 10.2169/internalmedicine.46.1813] [Medline: 17329917]

32. Heckemann B, Wolf A, Ali L, Sonntag SM, Ekman I. Discovering untapped relationship potential with patients in telehealth: a qualitative interview study. BMJ Open 2016 Mar 02;6(3):e009750 [FREE Full text] [doi: 10.1136/bmjopen-2015-009750] [Medline: 26936904]

33. Hubley S, Lynch SB, Schneck C, Thomas M, Shore J. Review of key telepsychiatry outcomes. World J Psychiatry 2016 Jul 22;6(2):269-282 [FREE Full text] [doi: 10.5498/wjp.v6.i2.269] [Medline: 27354970]

34. Cowan KE, McKean AJ, Gentry MT, Hilty DM. Barriers to use of telepsychiatry: clinicians as gatekeepers. Mayo Clin Proc 2019 Dec;94(12):2510-2523. [doi: 10.1016/j.mayocp.2019.04.018] [Medline: 31806104]

35. Epstein RM, Street Jr RL. Patient-Centered Communication in Cancer Care: Promoting Healing and Reducing Suffering. Bethesda, MD: National Cancer Institute, NIH Publication No. 07-6225; 2007:1-203.

36. Tickle-Degnen L, Rosenthal R. The nature of rapport and its nonverbal correlates. Psychol Inq 1990 Oct;1(4):285-293. [doi: 10.1207/s15327965pli0104 1]

37. Hansbrough W, Georges J. Validation of the presence of nursing scale using data triangulation. Nurs Res 2019;68(6):439-444. [doi: 10.1097/nnr.0000000000000381]

38. Haverfield MC, Tierney A, Schwartz R, Bass MB, Brown-Johnson C, Zionts DL, et al. Can patient-provider interpersonal interventions achieve the quadruple aim of healthcare? A systematic review. J Gen Intern Med 2020 Jul 09;35(7):2107-2117. [doi: 10.1007/s11606-019-05525-2] [Medline: 31919725]

39. Aldaz BE, Treharne GJ, Knight RG, Conner TS, Perez D. Oncology healthcare professionals' perspectives on the psychosocial support needs of cancer patients during oncology treatment. J Health Psychol 2017 Sep 01;22(10):1332-1344. [doi: 10.1177/1359105315626999] [Medline: 26837692]

40. Boston P, Bruce A. Palliative care nursing, technology, and therapeutic presence: are they reconcilable? J Palliat Care 2018 Dec 19;30(4):291-293. [doi: 10.1177/082585971403000409]

41. Thorne SE, Kuo M, Armstrong E, McPherson G, Harris SR, Hislop TG. 'Being known': patients' perspectives of the dynamics of human connection in cancer care. Psychooncology 2005 Oct;14(10):887-898. [doi: 10.1002/pon.945] [Medline: 16200520]

42. Grover C, Mackasey E, Cook E, Nurse H, Tremblay L, Clinician N, et al. Patient-reported care domains that enhance the experience of "being known" in an ambulatory cancer care centre. Can Oncol Nurs J 2018 Jul 19;28(3):166-171 [FREE Full text] [doi: $\underline{10.5737 / 23688076283166171]}$ [Medline: 31148824$]$

43. O'Grady C, Dahm MR, Roger P, Yates L. Trust, talk and the dictaphone: tracing the discursive accomplishment of trust in a surgical consultation. Discourse Soc 2013 Aug 08;25(1):65-83. [doi: 10.1177/0957926513496354]

44. Crawford T, Roger P, Candlin S. Tracing the discursive development of rapport in intercultural nurse-patient interactions. Int J Appl Linguist 2017 Feb 07;27(3):636-650. [doi: 10.1111/ijal.12166]

45. Komatsu H, Yagasaki K. The power of nursing: guiding patients through a journey of uncertainty. Eur J Oncol Nurs 2014 Aug;18(4):419-424 [FREE Full text] [doi: 10.1016/j.ejon.2014.03.006] [Medline: 24721178]

46. Radwin LE, Farquhar SL, Knowles MN, Virchick BG. Cancer patients' descriptions of their nursing care. J Adv Nurs 2005 May;50(2):162-169. [doi: 10.1111/j.1365-2648.2005.03375.x] [Medline: 15788080]

47. Rchaidia L, Dierckx de Casterlé B, De Blaeser L, Gastmans C. Cancer patients' perceptions of the good nurse: a literature review. Nurs Ethics 2009 Oct 11;16(5):528-542. [doi: 10.1177/0969733009106647] [Medline: 19671641]

48. McCorkle R, Ercolano E, Lazenby M, Schulman-Green D, Schilling LS, Lorig K, et al. Self-management: enabling and empowering patients living with cancer as a chronic illness. CA Cancer J Clin 2011;61(1):50-62 [FREE Full text] [doi: 10.3322/caac.20093] [Medline: 21205833]

49. Prip A, Møller KA, Nielsen DL, Jarden M, Olsen M, Danielsen AK. The patient-healthcare professional relationship and communication in the oncology outpatient setting. Cancer Nurs 2018;41(5):11-22. [doi: 10.1097/ncc.0000000000000533]

50. Coolbrandt A, de Casterlé B, Wildiers H, Aertgeerts B, Van der Elst E, van Achterberg T, et al. Dealing with chemotherapy-related symptoms at home: a qualitative study in adult patients with cancer. Eur J Cancer Care (Engl) 2016 Jan 06;25(1):79-92. [doi: 10.1111/ecc.12303] [Medline: 25752741]

51. McKenzie H, Hayes L, White K, Cox K, Fethney J, Boughton M, et al. Chemotherapy outpatients' unplanned presentations to hospital: a retrospective study. Support Care Cancer 2011 Jul 25;19(7):963-969. [doi: 10.1007/s00520-010-0913-y] [Medline: 20499108]

52. Thorne S, Oliffe J, Stajduhar K, Oglov V, Kim-Sing C, Hislop T. Poor communication in cancer care. Cancer Nurs 2013;36(6):445-453. [doi: 10.1097/ncc.0b013e31827eeda4]

53. Bohannon LS, Herbert AM, Pelz JB, Rantanen EM. Eye contact and video-mediated communication: a review. Displays 2013 Apr;34(2):177-185. [doi: 10.1016/j.displa.2012.10.009] 
54. Sävenstedt S, Zingmark K, Hydén L, Brulin C. Establishing joint attention in remote talks with the elderly about health: a study of nurses' conversation with elderly persons in teleconsultations. Scand J Caring Sci 2005 Dec;19(4):317-324. [doi: 10.1111/j.1471-6712.2005.00346.x] [Medline: 16324054]

55. Hammersley V, Donaghy E, Parker R, McNeilly H, Atherton H, Bikker A, et al. Comparing the content and quality of video, telephone, and face-to-face consultations: a non-randomised, quasi-experimental, exploratory study in UK primary care. Br J Gen Pract 2019 Oct;69(686):595-604 [FREE Full text] [doi: 10.3399/bjgp19X704573] [Medline: 31262846]

56. Sandelowski M. Whatever happened to qualitative description? Res Nurs Health 2000 Aug;23(4):334-340. [doi: 10.1002/1098-240x(200008)23:4<334::aid-nur9>3.0.co;2-g]

57. Sandelowski M. What's in a name? Qualitative description revisited. Res Nurs Health 2010 Mar;33(1):77-84. [doi: 10.1002/nur.20362] [Medline: 20014004]

58. Yilmaz K. Comparison of quantitative and qualitative research traditions: epistemological, theoretical, and methodological differences. Eur J Edu 2013 May 08;48(2):311-325. [doi: 10.1111/ejed.12014]

59. Sandelowski M. Sample size in qualitative research. Res Nurs Health 1995 May;18(2):179-183. [doi: 10.1002/nur.4770180211] [Medline: 7899572]

60. Marshall C, Rossman GB. Designing Qualitative Research - Sixth Edition. Los Angeles: SAGE Publications, Inc; $2016: 1-352$.

61. White C, Hardy J. What do palliative care patients and their relatives think about research in palliative care?-a systematic review. Support Care Cancer 2010 Aug 25;18(8):905-911. [doi: 10.1007/s00520-009-0724-1] [Medline: 19705165]

62. LeBlanc TW, Lodato JE, Currow DC, Abernethy AP. Overcoming recruitment challenges in palliative care clinical trials. J Oncol Pract 2013 Dec;9(6):277-282 [FREE Full text] [doi: 10.1200/JOP.2013.000996] [Medline: 24130254]

63. Archibald MM, Ambagtsheer RC, Casey MG, Lawless M. Using zoom videoconferencing for qualitative data collection: perceptions and experiences of researchers and participants. Int J Qual Methods 2019 Sep 11;18:A. [doi: $10.1177 / 1609406919874596]$

64. Deakin H, Wakefield K. Skype interviewing: reflections of two PhD researchers. Qual Res 2013 May 24;14(5):603-616. [doi: $10.1177 / 1468794113488126]$

65. Jovchelovitch S, Bauer M. Narrative interviewing. In: Bauer M, Gaskell G, editors. Qualitative Researching With Text, Image and Sound: A Practical Handbook for Social Research. London, United Kingdom: SAGE Publications Ltd; 2000:57-74.

66. Elo S, Kyngäs H. The qualitative content analysis process. J Adv Nurs 2008 May;62(1):107-115. [doi: 10.1111/j.1365-2648.2007.04569.x] [Medline: 18352969]

67. Hsieh H, Shannon SE. Three approaches to qualitative content analysis. Qual Health Res 2005 Dec;15(9):1277-1288. [doi: 10.1177/1049732305276687] [Medline: 16204405]

68. Glesne C. Becoming Qualitative Researchers: An Introduction. Boston, MA: Pearson; 2016.

69. Miles M, Huberman A, Saldaña J. Qualitative Data Analysis: A Methods Sourcebook. Thousand Oaks, CA: SAGE publications; 2020.

70. Morse JM, Barrett M, Mayan M, Olson K, Spiers J. Verification strategies for establishing reliability and validity in qualitative research. Int J Qual Methods 2002;1(2):13-22. [doi: 10.1177/160940690200100202]

71. Thorne S. The Great Saturation Debate: what the "S Word" means and doesn't mean in qualitative research reporting. Can J Nurs Res 2020 Mar 13;52(1):3-5. [doi: 10.1177/0844562119898554] [Medline: 31928347]

72. Elo S, Kääriäinen M, Kanste O, Pölkki T, Utriainen K, Kyngäs H. Qualitative content analysis: a focus on trustworthiness. SAGE Open 2014 Feb 11;4(1):A. [doi: 10.1177/2158244014522633]

73. Tracy SJ. Qualitative Quality: eight “Big-Tent” criteria for excellent qualitative research. Qual Inq 2010 Oct 01;16(10):837-851. [doi: 10.1177/1077800410383121]

74. Tong A, Sainsbury P, Craig J. Consolidated criteria for reporting qualitative research (COREQ): a 32-item checklist for interviews and focus groups. Int J Qual Health Care 2007 Dec;19(6):349-357. [doi: 10.1093/intqhc/mzm042] [Medline: 17872937]

75. Hastings SN, Mahanna EP, Berkowitz TS, Smith VA, Choate AL, Hughes JM, et al. Video-enhanced care management for medically complex older adults with cognitive impairment. J Am Geriatr Soc 2021 Jan 23;69(1):77-84. [doi: 10.1111/jgs.16819] [Medline: 32966603]

76. Oliver DP, Albright DL, Kruse RL, Wittenberg-Lyles E, Washington K, Demiris G. Caregiver evaluation of the ACTIVE intervention: "it was like we were sitting at the table with everyone". Am J Hosp Palliat Care 2014 Jul 26;31(4):444-453 [FREE Full text] [doi: 10.1177/1049909113490823] [Medline: 23713130]

77. Sharma U, Clarke M. Nurses' and community support workers' experience of telehealth: a longitudinal case study. BMC Health Serv Res 2014 May 10;14:164 [FREE Full text] [doi: 10.1186/1472-6963-14-164] [Medline: 24721599]

78. Solli H, Hvalvik S, Bjørk IT, Hellesø R. Characteristics of the relationship that develops from nurse-caregiver communication during telecare. J Clin Nurs 2015 Jul;24(13-14):1995-2004 [FREE Full text] [doi: 10.1111/jocn.12786] [Medline: 25659176]

79. Read Paul L, Salmon C, Sinnarajah A, Spice R. Web-based videoconferencing for rural palliative care consultation with elderly patients at home. Support Care Cancer 2019 Oct 7;27(9):3321-3330. [doi: 10.1007/s00520-018-4580-8] [Medline: $\underline{30613908]}$ 
80. Ritchey KC, Foy A, McArdel E, Gruenewald DA. Reinventing palliative care delivery in the era of COVID-19: how telemedicine can support end of life care. Am J Hosp Palliat Care 2020 Dec 07;37(11):992-997 [FREE Full text] [doi: 10.1177/1049909120948235] [Medline: 32762477]

81. Hibbert D, Mair FS, May CR, Boland A, O'Connor J, Capewell S, et al. Health professionals' responses to the introduction of a home telehealth service. J Telemed Telecare 2004 Jun 24;10(4):226-230. [doi: 10.1258/1357633041424386] [Medline: 15273033]

82. Pappas Y, Vseteckova J, Mastellos N, Greenfield G, Randhawa G. Diagnosis and decision-making in telemedicine. J Patient Exp 2019 Dec 08;6(4):296-304 [FREE Full text] [doi: 10.1177/2374373518803617] [Medline: $\underline{31853485]}$

83. Tachakra S, Rajani R. Social presence in telemedicine. J Telemed Telecare 2002 Jun 24;8(4):226-230. [doi: 10.1258/135763302320272202] [Medline: 12217106]

84. Martinez RC. "Lost Touch" : Situating human-connectedness in technology-caring in the health sciences. J Med Invest 2019;66(1.2):12-14 [FREE Full text] [doi: 10.2152/jmi.66.12] [Medline: 31064923]

85. Joy M, McGagh D, Jones N, Liyanage H, Sherlock J, Parimalanathan V, et al. Reorganisation of primary care for older adults during COVID-19: a cross-sectional database study in the UK. Br J Gen Pract 2020 Aug;70(697):540-547 [FREE Full text] [doi: 10.3399/bjgp20X710933] [Medline: $\underline{\text { 32661009] }}$

86. Paterson C, Bacon R, Dwyer R, Morrison KS, Toohey K, O'Dea A, et al. The role of telehealth during the COVID-19 pandemic across the interdisciplinary cancer team: implications for practice. Semin Oncol Nurs 2020 Dec;36(6):151090 [FREE Full text] [doi: 10.1016/j.soncn.2020.151090] [Medline: $\underline{\text { 33218886] }}$

87. Sim AJ, Redler G, Peacock J, Naso C, Wasserman S, McNitt KB, et al. Harnessing COVID-driven technical innovations for improved multi-disciplinary cancer care in the post-COVID era: the virtual patient room. Cancer Control 2020;27(1):A [FREE Full text] [doi: 10.1177/1073274820964800] [Medline: 33023342]

\section{Abbreviations}

IRB: institutional review board

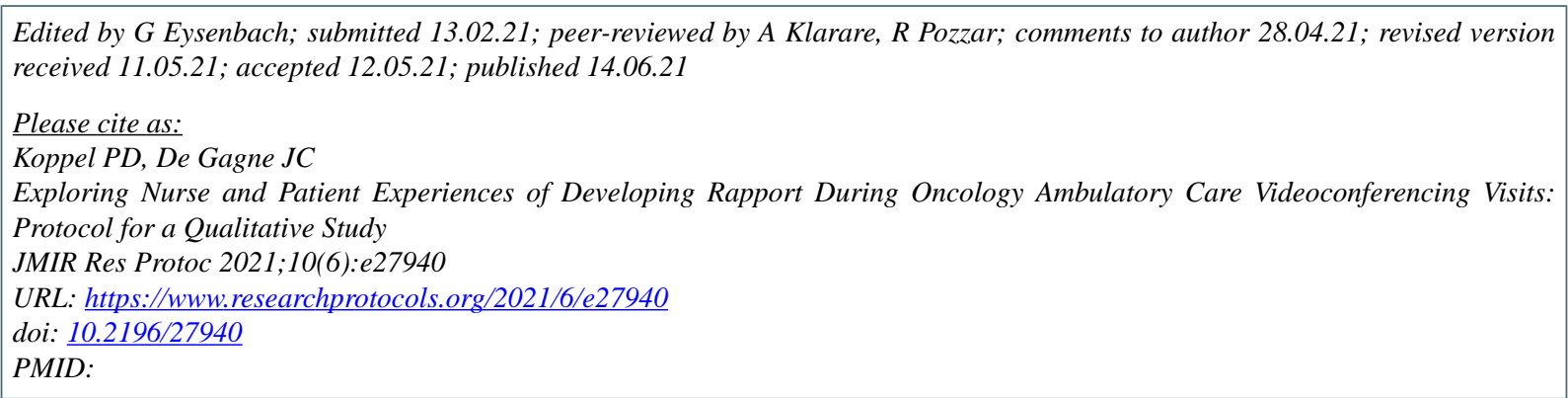

CPaula D Koppel, Jennie C De Gagne. Originally published in JMIR Research Protocols (https://www.researchprotocols.org), 14.06.2021. This is an open-access article distributed under the terms of the Creative Commons Attribution License (https://creativecommons.org/licenses/by/4.0/), which permits unrestricted use, distribution, and reproduction in any medium, provided the original work, first published in JMIR Research Protocols, is properly cited. The complete bibliographic information, a link to the original publication on https://www.researchprotocols.org, as well as this copyright and license information must be included. 